\title{
A Study on the Fire Spread Model of Wooden Buildings in Japan
}

\author{
YOSHIRO NAMBA and KENJIRO YASUNO \\ Japanese Association of Fire Science and Engineering \\ Department of Architecture, Faculty of Engineering, Kinki University \\ 1000 Hiromachi, Kure-city, Hiroshima, Japan
}

\section{ABSTRACT}

This paper deals with the fire spread within and between wooden buildings in Japan. The relation of the burnt area and the time draws approximately an S-curve. As former theories fail to estimate the real fire spread condition correctly, we have examined a polynomial curve and a logistic one as the most appropriate substitutes. According to the method of MAICE proposed by Dr. Akaike (1973), the optimal degree of the polynomial is shown to be three. But the polynomial does not fit the real fire spread phenomenon because it does not always follow a monotone function. Thus we have suggested that the logistic curve is good enough to explain the fire spread phenomenon. But our model exhibits a symmetry at the point of inflection. As the fire spread phenomenon is not guaranteed to have a symmetry, we have examined a more general type of logigtic curve which discribes the fire spread.

In case of determining the parameters of the logistic curve, we should strictly use the nonlinear least squares method as we have already reported in our former studies. By analyzing the data of real fire experiment by this method, we have obtained a very significant result, and also wish to refer to the method of improving the determination method of the parameters of the fire spread model.

\section{INTRODUCTTON}

In most Japanese cities and towns, the percentage of wooden buildings and the building-to-land ratio are relatively high. Therefore once a fire breaks out, there is a danger of being burnt down together with neibouring area. Many conflagrations have thus happened in Japan till about 1960 's. Consequently, many fire spread formulas have been developed as mentioned in the next section. They were useful for planning measures of the fire prevention, the fire fighting and so forth. However, they were based on the data of conflagrations till about 1945 and the fire spread velocity by their formulas seems to have become out-dated, for present conditions of cities, buildings and fire fighting measures have profoundly changed since 1945. Today in Japan, small fires often break out and they catch several buildings at most. However, this facts does not mean that there is no more danger of confraglations. For example, it is said that there can still be in Japan a danger of conflagrations when the fire fighting ability is 
lost in such as a case of great earthquakes.

Recently, the authors have developed a model of fire spread by analyzing the fire data of real experiment in 1980 by Fire Research Institute, Ministry of Home affaires, Government of Japan(1982,1983). These data show that the relationship between the burnt area and the time discribes approximately an S-curve. This means that former formulas fail to estimate the state of the real fire spread correctly. As a result, we have examined the polynomial and logistic curves in our studies, by assuming them better substitutes. According to the method of MAICE proposed by Dr. Akaike (1973), the optimal degree of polynomial is shown to be three. But the polynomial does not fit the real fire spread phenomenon because it is not always a monotonial. On the other hand, it appears that a logistic curve function is good enough to explain the fire spread phenomenon.

But our model exhibits a symmetry about the point of inflection. As it is difficult to assume that a fire spread phenomenon would be symmetrical, we have examined mathematically a more general type of logistic curve of the fire spread model.

This paper discusses the best type of function to discribe the growth of fire in wooden buildings and the best way to determine the required constants using the data from a typical fire. This is a mathematical model because most of the real fires show in Japan a similar tendency to the data.

\section{REVIEWS OF FIRE SPREAD FORMULAS AND MODEISS OF WOODEN BUILDINGS IN JAPAN}

\subsection{A Brief Review of Literature}

Empirical formulas of fire spreading speed have been proposed by Suzuki and Kinbara (1940), the Study team of Fire Prevention of Tokyo (1942), Tosabayashi (1947), Hamada (1951), Hishida (1954), and Horiuchi(1961). Further, Fujita (1975) and Sakai (1983) developed simulation models of the fire-spreading based on Hamada's formula. These formulas and simulation models have been developed on the basis of fire data before 1945. Therefore, it is doubtful to apply those formulas to modern urban area where the structure of houses and buildings have greatly changed since 1945. In fact, it is pointed out by Sasaki (1976) and Yamashita (1977) that Hamada's and Horiuchi's formulas tend to overestimate the fire-spreading speed. Moreover these formulas do not follow an S-curve.

\subsection{Progress of authors' studies}

We have developed recently a model of fire spread by analyzing the fire data of real experiments by Fire Research Institute, Government of Japan. It is obvious at a glance of the data that the relationship between the burnt area and the time constitutes approximately an S-curve as shown in Fig. 1. The dots in Fig.1 are the observed values. The smaller curves are indicated the state of fire spread for each building. The large curve is the state of fire spread of four buildings as a whole. Each building is similar to each other, and the conditions of experiment are in brief as follows:

(1) Structure : Wooden and one-story

(2) The average of building area : $132 \mathrm{~m}^{2}$

(3) The average distance between buildings : $4.5 \mathrm{~m}$

(4) The average of wind velocity : $1.8 \mathrm{~m} / \mathrm{sec}$ 


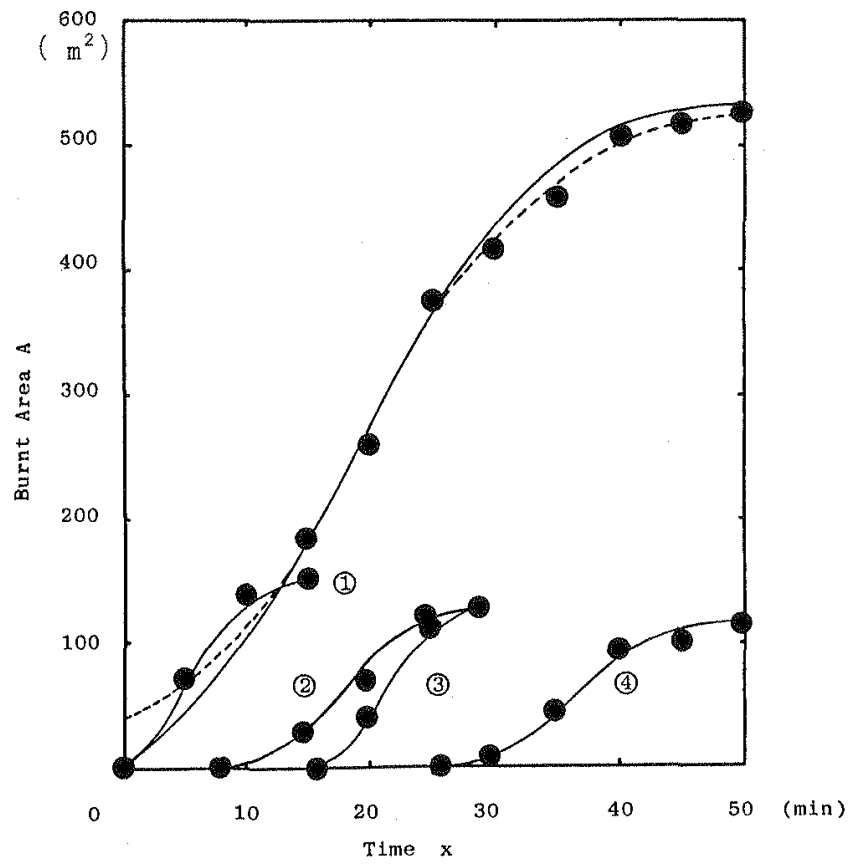

Fig. 1 The relation of the Burnt Area A and the Time $x$ : (After the fire experiment data at Saganoseki by Fire Research Institute, Government of Japan ; The dots are observed values.; (1) - (4) are the building numbers.)

(5) The method of ignition : Dividing the house into two equal parts, the fire was started at about the center of the two parts each.

Former theories as reviewed in foregoing section fail to explaine the real fire spread condition correctly. As the most appropriate expression, we have examined a polynominal curve and a logistic one. By the method of MAICE (Minimum Akaike Information Criterion Estimation) proposed by Dr. Akaike, the optimal degree of polynomial can be determined. Fig.2 shows the relationship between the value of AIC ( Akaike Information Criterion) and degree of polynomial.

The value of AIC is given by

$$
A I C=n \cdot \log (2+n)+n \cdot \log (S)+n+2 \cdot(m+2)
$$

where $n$ is the number of data and $m$ is the degree of polynomial. $S$ is sum of squares residual and $\log$ is natural logarithm.

As the optimal degree is the case when the value of AIC is minimum, the optimal degree is shown to be three from Fig.2. But the polynomial does not fit the real fire spread phenomenon because it is not always a monotonial. On the other hand, the function of logistic curve is good enough to explain the fire spread phenomenon.

The function of logistic curve given by 


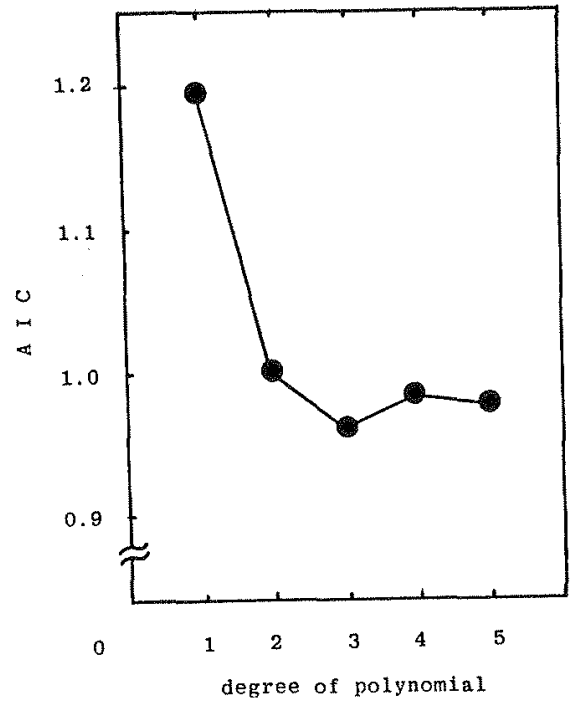

Fig.2 The relation of $\mathrm{AIC}$ and and degree of polynomial as a fire spread model
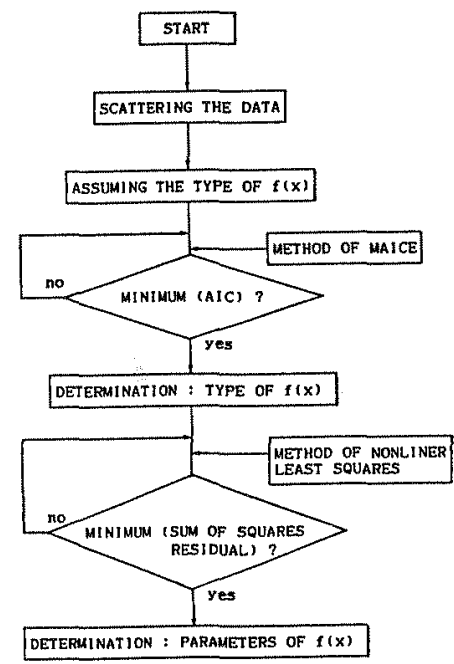

Fig.3 Schematic diagram of determining the parameters of $f(x)$ : In this case, $f(x)$ is considerd polynomial.

$$
A=\frac{G}{1+\exp (-a(x-c))}
$$

where $A\left(m^{2}\right)$ is burnt area at the time $x(m i n), G\left(m^{2}\right)$ is the maximum area of wooden buildings that is vulnerable to fire spread. The values of $a$ and $c$ are parameters to be determined statistically by the data. By using above data, parameters of a and $c$ is estimated to be 0.130 and 19.3 respectively by the nonlinear least squares method. This curve is drawn with dotted line in Fig.1. It is not convenient that A does not equal zero if $x=0$ and also $A$ does not equal $G$ if $x=x_{i}$. $x_{i}$ is the burning-out time of building area $G\left(\mathrm{~m}^{2}\right)$. Thus we modified the equation (2) as follows:

$$
A=\frac{G+d_{1}}{1+\exp (-a(x-c))}-\frac{G+d_{1}}{1+\exp (a c)}
$$

where $d_{1}$ is a modified coefficient given by

$$
a_{1}=\frac{1+2 \cdot \exp \left(-a x_{i}+a c\right)+\exp \left(-a x_{i}+2 \cdot a c\right)}{\exp (a c)-\exp \left(-a x_{i}+a c\right)}
$$

In this case, $d_{1}$ is about 46.2 and this curve is drawn with the solid lines in Fig. 1 . 


\section{ANALYSIS OF THE NEW MODEL : THEORETICAL REMARKS}

Our fire spread model formulated by equation (2) has a symmetry about the point of inflection. As the fire spread phenomenon does not always exhibit a symmetry, we have investigated a more generalized model of fire spread.

Equation (2) has a property of symmetry diagrammatically because a part of exponent is a linear function of $x$. If we choose another function, described $f(x)$ as arbitrary function of $x$, the generalized equation is given by

$$
A=\frac{G}{1+\exp (f(x))}
$$

or

$$
\log (G / A-1)=f(x)
$$

What kind of function is suitable to $f(x)$, depends upon the data. If $y=\log (G / A-1)$, then this is no more than a problem of curve fitting to be determined statistically by the data set of $x$ and $y$. In the case of equation (2), $f(x)$ is considered a monomial. It is possible to consider that $f(x)$ is a polynomial. If $f(x)$ is asummed as polynomial of $m$ degree, then

$$
f(x)=b_{0}+b_{1} \cdot x+b_{2} \cdot x^{2} \cdots+b_{m} \cdot x^{m}
$$

The optimal degree of polynomial can be estimated by the method of MAICE which is already mentioned in the previous section.

There is no difficulty in being regarded the error of $A$ as normal distribution statistically because A is the value of observation. But error of $y=\log (G / A-1)$ is not considered normal distribution because the error of $A$ is considered of normal distribution. It is impertinent to determine the parameters of polynomial by the method of least squares to equation (6), because the basic assumption of the method of least squares is that the variables of data are considered normal distribution. Equation (6) is used for the purpose of determining the type of function $\mathrm{f}(\mathrm{x})$ only. In order to estimate the parameters of $f(x)$ strictly, we should apply to the method of nonlinear least squares for equation (5). This methodology is indicated by Fig.3. Here we would like to submit our opinion about the conditions of model formulation, summarized as follows:

(1) The property of the curve must be constituted with observed data. For example, it is necessary to satisfy with initial and boundary conditions as strictly as possible.

(2) The tendency of the curve is not contradictory to the phenomenon. For example, if the phenomenon has a property of monotone increment, the curve should not vibrate.

(3) The difference between the observed values and predicated ones must be as small as possible.

In order to make the equation (6) satisfy the above condition (1), we modified the equation (6) as follows: 


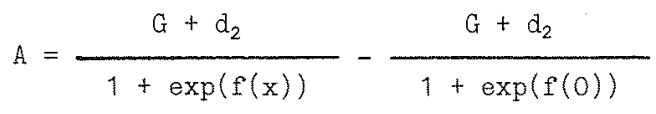

where

$$
d_{2}=\frac{1+2 \cdot \exp \left(f\left(x_{i}\right)\right)+\exp \left(f\left(x_{i}\right)+f(0)\right)}{\exp (f(0))-\exp \left(f\left(x_{i}\right)\right)} \cdot G
$$

\section{RESULTS AND DISCUSSION}

In Fig.4, the relationship between $y=(G / A-1)$ ard $x$ in Eq. (6) is plotted. The points are totalled nine that are obtained from the whole fire of four buildings. If the function of this relationship is asummed polynomial, the optimal degree can be determined by the method of MAICE as described in the previous section. The optimal case is defined that the value of AIC given by $\mathrm{Eq} \cdot(1)$ is minimum. The value of AIC were calculated for several cases and then the relationship between AIC and the degree of polynomial is shown in Fig.5. From this, the optimal function is known as trinomial. This is written by

$f(x)=b_{0}+b_{1} \cdot x+b_{2} \cdot x^{2}+b_{3} \cdot x^{3}$

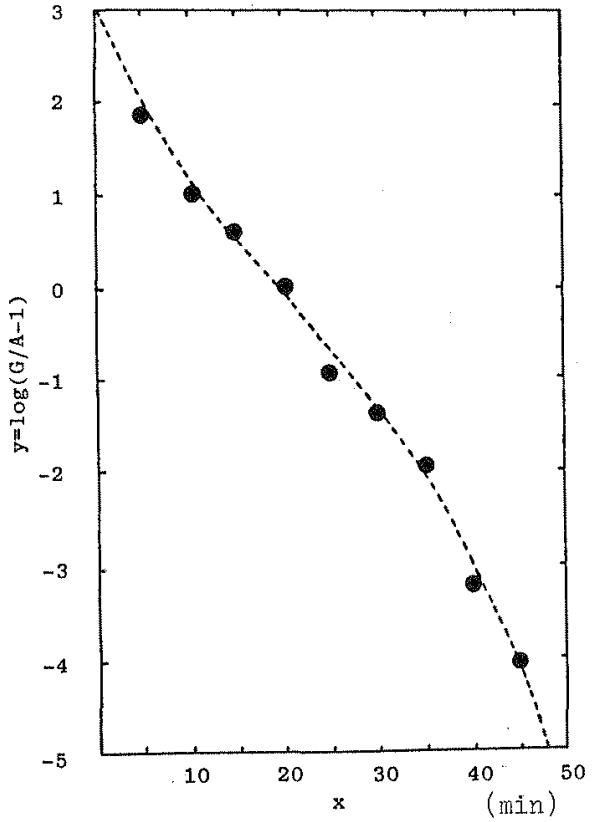

Fig. 4 The relation of $y=\log (G / A-1)$ and $x$ in equation (6)

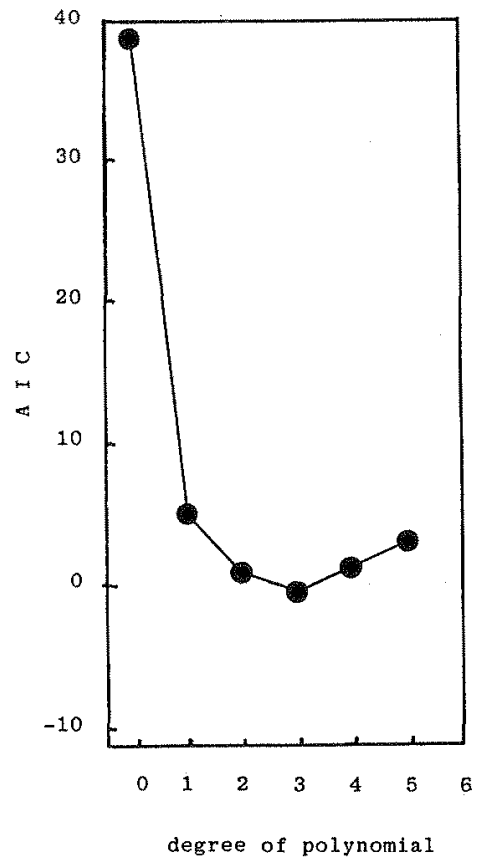

Fig. 5 The relation of AIC and degree of polynomial as $f(x)$ in equation (6) 
Where the unit of time for $x$ is hour in view of circumstancies of the calculation. In order to estimate the parameters of $f(x)$ strictly, we would submit that the method of nonlinear least squares should be applied for Eq. (5). But conventional methods such as the log-transformed type of $\mathrm{Eq} \cdot(6)$ applying the method of ordinary least squares, though simple and convenient, is impertinent. In recent years, the computer and its argorithms have made rapid progress and the computer programs of the method of nonlinear least squares have been developed such as NOLLS1 by $\mathrm{Mr}$. Tanabe (1981). The difference of the estimate parameters between both methods are indicated by Table 1. From this, the ratios of each parameter range from 0.96 to 1.87 and the nonlinear method of sum of squares residuel is smaller than the log-transformed one.

This means that the nonlinear method conforms to the data better.

Table 2 showns the sum of squares residual of the symmetric models ( $\mathrm{Eq} \cdot(2)$ and $\mathrm{Eq}(3)$ ) and the asymmetrical models ( $\mathrm{Eq} \cdot(5)$ and $\mathrm{Eq} \cdot(8)$ ). $\mathrm{Eq} \cdot(2)$ and $\mathrm{Eq} \cdot(5)$ are the prototype of these models. $\mathrm{Eq} \cdot(3)$ and $\mathrm{Eq} \cdot(8)$ are the modified equations in order to satisfy the condition (1) of model formulation. The sum of squares residual of each fire and whole one are indicated in table 2. From this, it is known that the sum of squares residual of the symmetric model is larger than the one of asymmetric model. This means that the symmetric model dose not conform to the data in comparison with the asymmetrical one.

Comparing the prototype and the modified one, neither of the two

is better at all studies. But modified one is superior to the prototype

in view of satisfication of the condition (1) of model formulation.

In Fig.6, the full line corresponds to the model of Eq. (8) and the dotted line corresponds to the model of Eq. (5) about the whole fire of four buildings.

Synthesizing the results of each paragraph of this paper, it becomes clear that $\mathrm{Eq} .(8)$ is a more general model for the fire spread of wooden buildings in Japan.

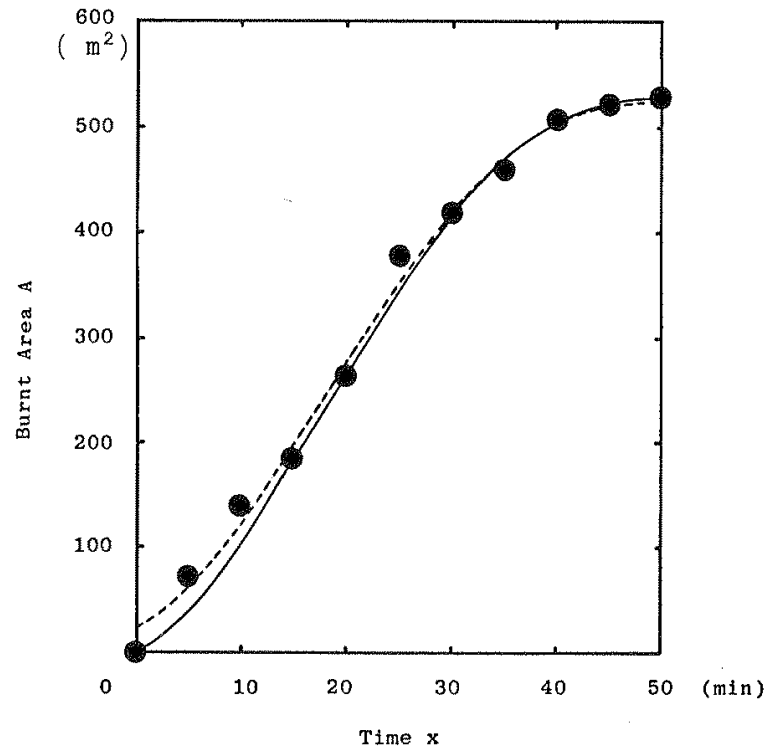

Fig.6 The relation of the Burnt Area $A$ and the Time $x$ as asylimetric model of $\mathrm{Eq} .(5)$ and $\mathrm{Eq} .(8)$ about the whole fire 
Table 1 Estimated parameters and sum of squares residual of trinomial

\begin{tabular}{|c|c|c|c|c|c|c|}
\hline & & $b_{0}$ & $\mathrm{~b}_{1}$ & $b_{2}$ & $\mathrm{~b}_{3}$ & $S$ \\
\hline $\begin{array}{l}\text { Building } \\
\text { NO.1 }\end{array}$ & $\begin{array}{l}\text { (a) log-tris. } \\
\text { (b) nonlinear } \\
\text { (b) } / \text { (a) }\end{array}$ & $\begin{array}{l}2.714 \\
4.525 \\
1.67\end{array}$ & $\begin{array}{r}-39.57 \\
-69.75 \\
1.76\end{array}$ & $\begin{array}{r}121.8 \\
227.2 \\
1.87\end{array}$ & $\begin{array}{l}-291.7 \\
-280.2 \\
0.96\end{array}$ & $\begin{array}{r}446.477 \\
13.217 \\
0.0296\end{array}$ \\
\hline $\begin{array}{l}\text { Building } \\
\text { No.2 }\end{array}$ & $\begin{array}{l}\text { (a) log-trns. } \\
\text { (b) nonlinear } \\
\text { (b) } / \text { (a) }\end{array}$ & $\begin{array}{l}4.696 \\
4.646 \\
0.99\end{array}$ & $\begin{array}{r}-28.34 \\
-29.96 \\
1.06\end{array}$ & $\begin{array}{l}59.33 \\
79.42 \\
1.34\end{array}$ & $\begin{array}{c}-103.6 \\
-148.8 \\
1.44\end{array}$ & $\begin{array}{r}64.763 \\
38.296 \\
0.591\end{array}$ \\
\hline $\begin{array}{l}\text { Building } \\
\mathrm{NO} \cdot 3\end{array}$ & $\begin{array}{l}\text { (a) log-trns. } \\
\text { (b) nonlinear } \\
\text { (b) } / \text { (a) }\end{array}$ & $\begin{array}{l}3.034 \\
4.685 \\
1.54\end{array}$ & $\begin{array}{r}-35.26 \\
-59.69 \\
1.69\end{array}$ & $\begin{array}{r}106.5 \\
187.9 \\
1.76\end{array}$ & $\begin{array}{c}-340.6 \\
-364 \cdot 3 \\
1.07\end{array}$ & $\begin{array}{r}324.554 \\
174.483 \\
0.538\end{array}$ \\
\hline $\begin{array}{l}\text { Building } \\
\mathrm{NO} .4\end{array}$ & $\begin{array}{l}\text { (a) log-tmas. } \\
\text { (b) nonlinear } \\
\text { (b) } / \text { (a) }\end{array}$ & $\begin{array}{l}5.040 \\
5.995 \\
1.19\end{array}$ & $\begin{array}{r}-31.87 \\
-42.02 \\
1.32\end{array}$ & $\begin{array}{r}28.95 \\
51.91 \\
1.79\end{array}$ & $\begin{array}{c}-11.83 \\
-16.31 \\
1.38\end{array}$ & $\begin{array}{r}44.142 \\
17.453 \\
0.395\end{array}$ \\
\hline $\begin{array}{l}\text { The whole } \\
\text { fire }\end{array}$ & $\begin{array}{l}\text { (a) log-tmis. } \\
\text { (b) nonlinear } \\
\text { (b) } / \text { (a) }\end{array}$ & $\begin{array}{l}2.636 \\
3.070 \\
1.16\end{array}$ & $\begin{array}{r}-10.55 \\
-13.89 \\
1.32\end{array}$ & $\begin{array}{r}11.38 \\
19.11 \\
1.68\end{array}$ & $\begin{array}{c}-12.43 \\
-17.97 \\
1.45\end{array}$ & $\begin{array}{r}2487.96 \\
2067.22 \\
0.831\end{array}$ \\
\hline
\end{tabular}

(Abbreviations) log-trns. : the method of log-transformed type nonlinear : the method of nonlinear least squares $\mathrm{S}$ : sum of squares residual.

Table 2 Sum of squares residual of fire spread models

\begin{tabular}{|c|c|c|c|c|c|}
\hline & & No.1 & $\begin{array}{l}\text { for each buildi } \\
\text { No.2 }\end{array}$ & $\operatorname{lng}_{\mathrm{No}}$ & $\begin{array}{l}\text { The whole } \\
\text { fire }\end{array}$ \\
\hline symmetric & $\mathrm{Eq} \cdot(2)$ & 65.118 & $147.405241 \cdot 421$ & $112 \cdot 429$ & 2942.35 \\
\hline model & $\mathrm{Eq} \cdot(3)$ & 61.731 & $130.428 \quad 230.522$ & 103.122 & 4913.71 \\
\hline asymmetric & $\mathrm{Eq} \cdot(5)$ & 13.217 & $38.296 \quad 174.483$ & 17.453 & 2067.22 \\
\hline model & $\mathrm{Eq} \cdot(8)$ & 39.597 & 31.241221 .433 & $50 \cdot 445$ & 3358.76 \\
\hline
\end{tabular}




\section{CONCLUDING REMARKS}

The authors have reviewed former mathematical and statistical. fire spread formulas and models of wooden buildings in Japan. As a result, it is found out that former theories fail to explain real fire spread condition in present urban areas. The authors have therefore deveroped a new fire spread model. This paper consolidates the reports hitherto published by authors $(1982,1983)$ as well as newly obtained findings. A summary of our conclusion about the results is as follows:

(1) A polynomial model for the fire spread phenomenon would be best explained in a trinomial form. But this does not fit the real fire spread because it does not always constitute a monotone function.

(2) The logistic curve of Eq.(2) is good enough to explain the fire spread phenomenon consistently. As the modified model of $\mathrm{Eq} .(3)$ satisfies the condition (1) of model formulation, this is better than the prototype of $\mathrm{Eq} \cdot(2)$.

(3) But the above model exhibits a symmetry about the point of inflection. As it is difficult to assume that the fire spread phenomenon is symmetrical, we have examined a more general model. Synthesizing the results of each section of this paper, it becomes clear that Eq. (8) is a more general model for the fire spread of wooden buildings in Japan.

(4) Concerning the determination of parameters of nonlinear function, we should apply the method of nonlinear least squares and should not apply such method like the log-transformed method. In this study, the ratios of the difference of perameters between the nonlinear method and the log-transformed one range from 0.96 to 1.87 .

Because this study is the basic one on the fire spread model, we should make these fruitful conclusions apply the practical problems. For example, Dr. Kuroda and authers have recently applied these findings for the planning of aseismic fire cisterns in Japan (1985). Needless to say, the present study is as yet a very fundamental one, so that a number of questions remain to be further investigated for improving fire prevention planning.

\section{AKNOWLEGEMENTS}

The authors express their gratitude to the Fire Research Institute, Government of Japan, for providing useful data and are greatly indebted to $\mathrm{Dr}$. Tone for his helpful advice and to Mr. Tanabe for providing the computer program NOLLS1 of nonlinear least squares method. The authors also wish to thank Kinki University for the partial financial support for the study.

\section{NOMENCLATURE}

A : burnt area of floor $\left(\mathrm{m}^{2}\right)$

AIC : Akaike Information Criterion given by $\mathrm{Eq}_{1}$ (1)

a : coefficient of Eq. (2)

$b_{1}, b_{2} \cdots b_{m}$ : coefficient of polynomial

$c$ : coefficient of $\mathrm{Eq} \cdot(2)$

$\mathrm{d}_{1}$ : modified coefficient of $\mathrm{Eq} \cdot(4)$

$\mathrm{d}_{2}$ : modified coefficient of $\mathrm{Eq} \cdot(8)$

$G$ : building area $\left(\mathrm{m}^{2}\right)$ of floor that a fire is vulnerable to spread 


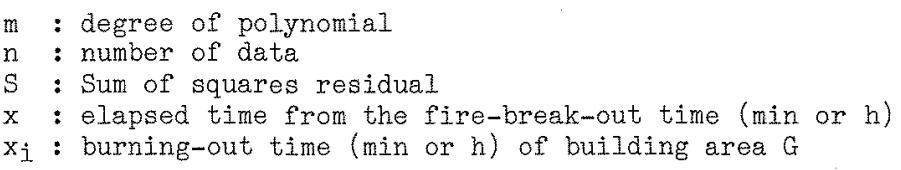

\section{REFERENCES}

1. Akaike, H. : Information Theory and An Extention of The Maximum Likelihood Principle, 2nd Inter. Symp. on Information Theory (Petrov, B. N. and Csaki, F. eds.), Akademiai Kiado, Budapest, 1973 (in English)

2. Yasuno, K. et al. : A basic study on fire spread of buildings, Bu11. of JAFSE, Vo1.31, No.1, 1982.a (in Japanese)

3. Yasuno, K. et al. : A basic study on fire spread formula of houses used by logistic curve, Trans. of AIJ, NO.311, 1982.b (in Japanese)

4. Yasuno, $K$. et al. : A basic study on effectiveness of suppressing building fire by water application, Bull. of JAFSE, Vol.31, No.2, 1982.c (in Japanese)

5. Yasuno, K. et al. : A basic study of fire spread formula (Iogistic curve) of wooden buildings by finite difference graphical method, Trans. of AIJ, No.311, 1983 (in Japanese)

6. Fire Research Institute, Ministry of Home Affaires, Government of Japan : Experimental Report on the Coutermeasures againt Large-Scale Fire by Using the Actual Buildings at Saganoseki, Fire Research Institute, 1980 (in Japanese)

7. Suzuki, S. and Kinbara, T. : On Fire spreading of a conflagration, Applied Physics, vol.9, No.10,1940 (in Japanese)

8. Study Team of Fire Prevention of Tokyo : Fire spread speed, Marin and Fire Insurance Association of Japan, 1942 (in Japanese)

9. Tosabayashi, T. : On Conflagration of Muramatsu, Marine and Fire Insurance Association of Japen, 1947 (in Japanese)

10. Hishida, K. : Arithmetic of fire risk level, Marine and Fire Insurance Association of Japan, 1947 (in Japanese)

11. Horiuchi, $S$. : Study on fire prevention facilities in urban area, a Dissertation submitted to Kyoto University, 1961 (in Japanese)

12. Fujita, T. : Model for fire spread and simulation, Research on Disaster, Vol.8, 1975 (in Japanese)

13. Sakai, K. : Study on Hamada's formula in view of burnt area and movement of fire spreading, City Planning Review Vol.18, 1975 (in Japanese)

14. Sasaki, H. : Road width and fire spread, Trans. of Scientific Lecture meeting of AIJ, 1983 (in Japanese)

15. Yamashita, K. et al. : Report of fire spreading conditions of Sakata conflagration (I) - (IV), Fire, Vol.72, No.2-6, 1977 (in Japanese)

16. Tanabe, K. et al. : NOLLS1, A FORTRAN subroutine for nonlinear least squares by quasi-Newton method, Computer science monographs, The Institute of Statistical Mathematics, Tokyo, 1981 (in English)

17. Kuroda, K. et al. : Decision theoretic approch to location planning of aseismic fire cisterns, Proceedings of JSCE, No.353, 1985 (in English)

Abbreviations

AIJ : Architecutural Institute of Japan

JAFSE : Japanese Association of Fire Science and Engineering

JSCE : Japan Society of Civil Engineers 